\title{
A cross-sectional survey to compare the competence of learners registered for the Baccalaureus Curationis programme using different learning approaches at the University of the Western Cape
}

\author{
Authors: \\ Loretta Z. le Roux ${ }^{1}$ \\ Thembisile D. Khanyile ${ }^{1}$ \\ Affiliations: \\ ${ }^{1}$ School of Nursing, University \\ of the Western Cape, \\ South Africa \\ Correspondence to: \\ Loretta le Roux \\ Email: \\ Ileroux@uwc.ac.za \\ Postal address: \\ 42 Colneus Street, Vredelust, \\ Kuilsriver, 7580 \\ Dates: \\ Received: 02 Sept. 2011 \\ Accepted: 18 Nov. 2011 \\ Published: 22 Feb. 2012 \\ How to cite this article: \\ Le Roux, L.Z. \& Khanyile, \\ T.D., 2012, 'A cross-sectional \\ survey to compare the \\ competence of learners \\ registered for the \\ Baccalaureus Curationis \\ programme using different \\ learning approaches at the \\ University of the Western \\ Cape, Curationis 34(1) \\ Art. 53, 7 pages. http:// \\ dx.doi.org/10.4102/ \\ curationis.v34i1.53
}

The purpose of the study was to compare the extent to which the different teaching approaches applied in the Baccalaureus Curationis programme adequately prepare graduating learners for professional competence. The research methodology was a quantitative approach, based on descriptive research, with a clinical competence development model to guide the data collection procedure. The target population of the study included a sample of 250 learners in the four-year B.Cur programme, that extended from first-to-fourth-year. Stratified random sampling was applied to select the sample learners for this research and data were collected by means of a five-point Likert scale questionnaire. Data were organised and managed using the SAS statistical software package. Descriptive statistics were gathered with measures of central tendency and dispersion included, and their findings were illustrated on descriptive tables. A correlation technique was applied to determine the effects of the independent variable on the dependent variable.

The results of the study indicated that progression in competence did not occur as learners progressed through higher levels of their training, except during the third-year of study. However, the study's results confirmed the strengths of the Case-based clinical reasoning approach to teaching and learning. This approach is able to combine the strengths of the traditional methods, which dealt with large class sizes and that had a focus on learner centred learning, with a focus on clinical practice. This approach provides realistic opportunities for learners to experiment with solutions to dilemmas encountered in real life situations, from the protected and safe environment of the classroom. The first-year learners who were observed in this study, who although novices, were exposed to Case-based teaching approaches and showed more self-perceived competence than learners in later years. This occurred in spite of the limited exposure of the first-year learners to real life clinical situations. The outcome of this study recommends that more studies are conducted, in the School of Nursing at the University of the Western Cape (UWC), to explore teaching and learning approaches that fully maximise the clinical and theoretical competencies of the learners. The outcome further recommends that learner-centred teaching approaches, such as Case-based method, are applied to all year levels of study in the B.Cur programme, due to its proven value when it was applied to first-year learners. The Case-based clinical reasoning approach to learning, that has been implemented at the school, promotes competence and self confidence in learners and has enhanced their sense of responsibility to be actively involved in their own learning.

\section{Introduction}

The School of Nursing at the University of the Western Cape has increased its enrolment limits from 80 to 300 per year since 2004. This increase in learner totals brought about challenges, especially in the quality of the academic programme offered. To balance equity of access with the quality of its academic enterprise, the school implemented the Case-based approach to teaching and learning. Traditional approaches, to teaching nursing learners, have relied on didactic approaches to learning. Faced with the challenge of large class sizes, it was imperative for academics at the School of Nursing to develop strategies that would ensure that the increased numbers did not compromise the quality of the academic programme. An additional challenge was the impact that the increased numbers had on the clinical learning environment, which was already strained by nurse shortages. Therefore, the School introduced the Case-based reasoning approach to learning. This approach adequately balances both classroom and clinical learning because its core concepts are clinical reasoning, critical thinking, problem solving and interpersonal skills. These core concepts are central to professional nursing practice. Clinical reasoning is a process that includes 
gathering and interpreting evidence to optimise the treatment of patients. It is a cognitive process of reviewing, analyzing patient data to plan their care and making decisions for positive patient outcomes (Higgs \& Jones 2000:107). The Case-based approach favours learning from experience and hence Kolb's experiential learning theory has been adopted as a theoretical framework for teaching and learning using this approach. Therefore the Case-based reasoning approach allows learners to integrate and apply clinical and basic scientific knowledge and skills such as clinical reasoning, critical thinking, problem solving and interpersonal skills to real or hypothetical case scenarios (Ertmer \& Russel 1995:23-31).

The implementation of the Case-based reasoning approach has been positively evaluated by learners since its inception in 2005. This innovation was implemented in a phased-inapproach starting with the first-year group in 2005. This paper presents the results of a quantitative study conducted to assess whether or not this approach increased the learners' level of competence, and if so, whether or not it increased in unison with their progression within the programme.

\section{Purpose and objectives of the study}

The purpose of the study was therefore to compare the extent to which the different teaching approaches, applied in the Baccalaureus Curationis programme, adequately prepare graduating learners for professional competence. The study is based on descriptive research.

\section{Theoretical framework and literature review}

Benner's model of skills acquisition (Benner 1984:13-34) was applied as a theoretical framework for the study. This study focused on how well the B.Cur programme prepared learners to fit the roles they are expected to perform after they complete the programme. Benner's model highlights the stages of gaining clinical competence, and was used to guide data collection, which focussed on skills acquisition and the progression of competence. The first four stages of this model were applied to data collection to measure improvement in performance from novice to proficient. The last stage was excluded as it relates to professional nurses.

\section{Stage 1: Novice}

Beginners have had no experience of the situations in which they are expected to perform. At this level, novices are mostly introduced to universally applied general context-free rules and fundamental principles. The assessment at this stage is mostly focused on rule governed performance.

\section{Stage 2: Advanced beginner}

At this level the learner has been exposed to some reallife practice experience. However, they are still heavily dependent on guided practice by a mentor.

\section{Stage 3: Competent}

They have been exposed to real-life clinical experience for enough time, usually two to three years, to be competent. They have well developed problem solving skills characterised by conscious, deliberate planning and the ability to execute care plans. Their experience is very focused on specific situations.

\section{Stage 4: Proficient}

They have a holistic view of a situation and they understand its meaning as they take long term goals into account. They source from their previous experience when making decisions about interventions.

\section{Definition of key concepts Competence}

This includes the knowledge, skills and attitudes that enable an individual to perform a role or a task up to a defined level (Uys 2003:29). Competence in this study refers to holistic learning that occurs at the cognitive, affective and psychomotor level.

\section{Case-based learning}

Case-based learning requires the active participation of learners in a real or hypothetical problem, and it reflects specific experiences which are common to the discipline under study (Ertmer \& Russell 1995:24).

\section{Learner}

A person who is learning something (South African Oxford Dictionary 2004:257). In this study 'learner' refers to all learners registered for the B.Cur programme at the University of the Western Cape from year level 1 to year level 4 .

\section{Assessment}

This is the process of collecting evidence and making judgments on whether or not competence has been achieved by the learner. It is measured on the basis of the learner's performance against certain criteria (Competency International 2000:6).

\section{Significance of the study}

The study's results confirmed that the Case-based clinical reasoning approach to teaching and learning was effective as a method for integrating both theoretical and clinical practice. This was important for the School due to the challenges that it experienced, namely of ensuring that the increase in learner enrolment does not compromise the quality of the academic standards.

\section{Research design}

The study employed a descriptive cross-sectional survey with a questionnaire to determine self-reported competency at the four levels of the programme.

\section{Population}

The target population included samples of B.Cur learners, from first-to-fourth-year level, at the Nursing Department of UWC. 


\section{Sampling}

Stratified random sampling was used to select the sample population for this research. This type of sampling was used because probability sampling reduces sampling errors and bias, while enhancing representation and the confidence of the sample (Hek, Judd \& Moule 2003:62).

Printouts of class lists from every year level registered for the B.Cur programme, in 2005 at the University of the Western Cape, were obtained and participants were selected from these lists. Questionnaires were administered to a sample of 250 participants, with the help of an assistant. The final sample size was 223. This included the 2005 first-year $(n=$ $90)$, second-year $(n=92)$, third-year $(n=21)$ and fourth-year $(n=20)$ learners.

\section{Data collection methods}

A questionnaire was prepared using a five-point Likert scale (1 = agree, 2 = strongly agree, 3 = don't agree or disagree, $4=$ strongly disagree, and $5=$ disagree), that only asked closeended questions. The instrument consisted of four sections, with each section emphasising how learners progress from novice to proficient, as guided by Benner's first four stages of clinical competence.

\section{Data analysis}

Data were managed for analysis by means of a statistical software package, known as SAS, with the inclusion of percentages to present the results. Descriptive data analysis measures were represented in the study, including percentages, tables, box and scatter plots. According to Brockopp and Hastings-Tolsma (1995:200), descriptive research approaches describe data in an easily understandable way. Spearman's rank order correlation was calculated as a measure of correlation, since all the variables were on an ordinal scale. Ordinal data measurements categorise data in rank order according to certain criteria, but they do not explicitly measure the differences between the data in relation to these specific criteria (Cormack 2000:25). Measures of central tendency - that is mode, mean and median - were worked out to identify systematic variations among the target population, and to identify central characteristics of the data. These were included to establish whether or not different feelings of competency existed among learner nurses at the different levels of the B.Cur programme.

\section{Presentation of the instrument}

All four sections of the instrument were applicable to all year levels in the B.Cur programme, in order to measure feelings of competence at different stages of training. Each section presented in the instrument was based on Benner's (1984) model of skills development. The following is a brief explanation of how these sections correspond to each of the model's first four stages, namely novice, advanced beginner, competent and proficient.
Items in section 1 of the instrument, that reflected feelings of competency most strongly, were based on the following criteria: 'the perception that nursing practice was easy and effortless', 'feeling anxious before starting clinical procedures', 'the level of competence at this particular level', 'the need for supervision during clinical procedures', 'identifying and improving strengths and weaknesses', 'whether or not practice was only guided by learned rules from the classroom', and 'having the ability to apply theory to practice'.

In section 2, feelings of competency were mostly emphasised through the following factors: 'the need for supervision', 'doing tasks accurately and thoroughly', 'whether problemsolving activities were difficult or not', 'taking responsibility for seeking and interpreting information without relying on classroom information alone', 'how adequately training prepared learners for clinical experiences', and 'confidence and assertiveness'.

Items in section 3, that highlighted feelings of competence, were the following: 'being competent implied being an expert', 'the role of prior experiences', 'confronting peers who practise unsafe nursing care', 'overseeing the work of peers', 'responding to patient needs without the urge to delegate it to others', 'the need for supervision', 'communication with doctors', and 'teaching and assessment of peers'.

Questions that strongly highlighted feelings of competence in section 4, included the following criteria: 'being competent implied being an expert', 'decision-making skills in emergency clinical situations', 'dealing with emergencies calmly and competently', 'being able to multi-task, as well as cope with interruptions at the same time', 'sensitivity to patient needs and preferences', 'doing tasks accurately and thoroughly', 'the need for supervision', 'recognising how nursing actions relate to an institution's long-term goals', and 'supervision and teaching of peers'.

\section{Reliability and validity}

To improve the reliability of the survey, a large sample population was selected and the instrument that measured the sample had a large item content. Some items across the four sections were constructed in more or less the same way in order to measure whether or not learners had answered these items consistently, and to observe how learners in different year levels felt about the same concept. This would identify characteristic differences between learners' descriptions of the same situation, principle or concept. In order to ensure content validity, the instrument was pilottested by administering it to $5 \%$ of the sample, and the participants were requested to indicate if they had difficulty in understanding the questionnaire's instructions or the meaning of words in the questionnaire. Subjects indicated no difficulty in answering the questionnaires, and no additional changes were thus made to the instrument. 


\section{Ethical considerations}

Permission to conduct this study was obtained from the head of the Nursing Department at the University of the Western Cape, and ethical clearance was obtained from the Higher Degree Committee of the Faculty of Community and Health Sciences at the university. Informed consent was obtained from all participants in the study, to indicate their voluntary participation in the study. Participants had the right to refuse disclosure of information or to withdraw from the research process at any time, had they the desire to do so, and were ensured that all information collected from this study would be treated anonymously and confidentially.

\section{Results}

Tables 1 to Table 4 present the means, medians, standard deviations, and the minimum and maximum values of the sum of the scores on questions in the particular sections that addressed competency. It specifically highlights mean score differences between year levels with regard to feelings of competency.

In Table 1, first-year learners, or novices, reflected the highest mean scores for section $1(M=22.518$ out of the highest possible score of 35), in Table 2, section $2(M=29,806$ out of the highest possible score of 40 ), as well as section 4 ( $M=43,378$ out of the highest possible score of 55) in Table 3. This finding suggests that first-years had higher feelings of competence, whether or not competence was measured at novice, advanced beginner or proficient levels.

In Table 4 , section 3 ( $M=35,926$ out of the highest possible score of 45) reflected that feelings of competence in thirdyear learners portrayed a steady increase from their first-year level up to their fourth-year. This was the only section where first-year learners reflected the least feelings of competence. Table 4 reveals mean scores in this section which ranged from 35,926 in the first-year to 38,263 in the fourth-year, out of the highest possible score of 45 .

Based on the findings, it can be summarised that feelings of competence did not essentially increase as the year level increased. Mean scores did not increase with time as such, but rather uneven scores were reflected from the above. The only positive direction followed was at the third-year level, where there was a steady increase in competence from year 1 to year 4 . The standard deviations among year levels were at times close, and at other times scattered, indicating that distinctive differences existed among the different groups.

Table 5 demonstrates that a weak correlation was found between Competence 1 and year ( $r h o=-0,15, p=0,028)$, and Competence 2 and year ( $r h o=-0,13, p=0,048)$, while a nonsignificant association existed between Competence 4 and year. These results confirmed that learners did not increase in their level of competence as they progressed to higher year levels. The only positive and significant relationship found was between Competence 3 and year $(r h o=0,18, p=0,011)$,
TABLE 1: Mean scores of the novice lear.

\begin{tabular}{llllll}
\hline Year of study & Mean & Median & s.d. $\uparrow$ & Minimum & Maximum \\
\hline First & 22.518 & 22.000 & 3.177 & 16.500 & 31.500 \\
Second & 20.866 & 20.750 & 3.167 & 13.500 & 29.500 \\
Third & 21.895 & 21.000 & 2.542 & 18.500 & 27.000 \\
Fourth & 21.368 & 23.000 & 3.511 & 12.500 & 26.000 \\
\hline
\end{tabular}

$\dagger$, s.d., Standard deviation.

TABLE 2: Mean scores of the advanced beginner.

\begin{tabular}{llllll}
\hline Year of study & Mean & Median & s.d. $\dagger$ & Minimum & Maximum \\
\hline First & 29.806 & 29.500 & 3.225 & 19.500 & 35.500 \\
Second & 28.328 & 29.000 & 3.766 & 17.000 & 35.500 \\
Third & 28.763 & 29.500 & 5.149 & 15.500 & 34.500 \\
Fourth & 28.150 & 29.000 & 5.259 & 16.500 & 37.500 \\
\hline
\end{tabular}

$\dagger$, s.d., Standard deviation.

TABLE 3: Mean scores of the proficient learner.

\begin{tabular}{llllll}
\hline Year of study & Mean & Median & s.d. $\dagger$ & Minimum & Maximum \\
\hline First & 43.378 & 43.500 & 4.802 & 35.000 & 53.000 \\
Second & 42.768 & 43.500 & 6.401 & 24.000 & 53.000 \\
Third & 42.825 & 43.750 & 5.209 & 30.500 & 52.500 \\
Fourth & 42.884 & 44.500 & 7.537 & 22.500 & 52.500 \\
\hline
\end{tabular}

$\dagger$, s.d., Standard deviation.

TABLE 4: Mean scores of the competent learner.

\begin{tabular}{llllll}
\hline Year of study & Mean & Median & s.d. $\dagger$ & Minimum & Maximum \\
\hline First & 35.926 & 35.000 & 4.297 & 24.000 & 45.500 \\
Second & 36.732 & 37.250 & 3.957 & 23.500 & 44.500 \\
Third & 37.235 & 38.500 & 4.158 & 30.500 & 44.500 \\
Fourth & 38.263 & 39.500 & 6.467 & 19.500 & 45.500 \\
\hline
\end{tabular}

$\dagger$, s.d., Standard deviation.

which supported the progression in feelings of competence with higher levels of education.

\section{Discussion}

The study's findings were inconclusive to support the research question that feelings of competence increased as the year of training increased. The results only partially supported the hypothesis that there would be a difference in the level of competence between learners at various levels of their study, as was seen among third-year learners, where feelings of competence increased as the year level increased.

\section{Feelings of competence in first-year learners}

A noteworthy fact was that junior learners showed higher feelings of competency, than more senior learners, in most of the sections. Benner (1984:13-34) describes the novice learners who, at the beginning of an educational programme, do not possess much pre-existing knowledge, and need considerable supervision and guidance. Rhodes and Curran (2005:260) support the fact that novice learners still require various learning experiences in order to facilitate the application of theory in practice. Although, at first-year, their clinical exposure to real life situations is limited, their feelings of competence increased with practice due to the Case-based clinical reasoning approach implemented at this level (Khanyile \& Mfidi 2005:74). This approach is oriented 
towards clinical reasoning. It is also consistent with the findings in the study by Hoke and Robbins (2005:349-353) who found that active learning strategies, such as smallgroup presentations and case studies, are useful to teach critical thinking skills and the application of classroomacquired knowledge in the clinical settings.

\section{Feelings of competence in second-year learners}

Second-year learners did not progress in competence as the year level increased. Benner (1984:13-34) indicated that prior experience allows advanced beginners to perform marginally acceptably, and improve their ability to relate concepts and rules to the greater clinical context. The advanced beginner does, however, still need much guidance and supervision, as well as more time to relate theory to clinical experience. Although second-year level learners have developed a sense of autonomy, their functioning is still inadequate. Teaching and assessment of the second-year learners in this study were heavily based on traditional educational approaches. Most of the teaching and learning strategies were more content-based and teacher-centred, rather than being performance-driven and learner-centred. This could be attributed to the fact that lecturers had to teach large classes. Piercey (1995:206-211) noted that traditional curricula are more content-focused, and may be easy to administer and control, but lack the ability to prepare learners to practice competently at the beginner level of their chosen profession.

Second-year learners continuously underwent clinical assessment, by means of a practice portfolio, which served as a collection of evidence of the outcomes that they attained. However, portfolios were only included as a product, aimed at scoring performance rather than development, and improving weaknesses through continuous feedback and reflective practice, which could cause serious gaps between theoretical and practical ability. If portfolio assessment is evaluated adequately, it can help to overcome the bridge between theory and practice. This will give learners the opportunity to prove, with evidence, how they have attained the required outcomes, how the experience has added to their personal and professional development, and help them to decide whether or not they still require further learning when they reflect on their experiences (Spence \& El-Ansari 2004:389; McMullan et al. 2002:291-292). The final assessment of the clinical practice of second-year learners was also based on the use of one instrument only, a rating scale, assessed through direct observation. Performance was therefore graded by means of a score. When a single instrument is used, its validity and reliability is questioned. It was found that learners obtained abnormally high scores, as high as $90 \%$, for a clinical assessment such as the administration of medication, when the learner still lacked the ability to solve calculation problems. This implied that the instruments lacked validity as they were more focused on measuring psychomotor skills, instead of capturing all three domains of development-knowledge, skill and attitude.

According to Neary (2001:15-16) the use of a single assessment procedure, such as direct observation, will lack validity and reliability and should be questioned in relation to assessor subjectivity. Neary (16) proposes that clinical assessment should rather be aimed at self-directed learning methods, such as learning contracts and contract assignments, as these will foster a more supportive and guided system for both learners and assessors. It is clear from the above how traditional methods of teaching and assessment could result in a learner's inability to acquire specific skills, knowledge and the attitude necessary to fulfil future workplace roles.

\section{Feelings of competence in third-year learners}

Besides the first-year group, third-year learners in the study felt increased feelings of competence as they progressed in their training. Results from third-year scores reflected that learners felt confident about their clinical and academic

TABLE 5: The correlation procedure.

\begin{tabular}{|c|c|c|c|c|c|c|c|}
\hline \multicolumn{2}{|c|}{ Correlation matrix } & \multirow[t]{2}{*}{ Year } & \multicolumn{4}{|c|}{ Competence } & \multirow[t]{2}{*}{ Total } \\
\hline & & & 1 & 2 & 3 & 4 & \\
\hline \multirow[t]{3}{*}{ Yeat } & Correlation coefficient & 1 & -0.15184 & -0.13489 & 0.18225 & -0.00053 & -0.01785 \\
\hline & $P$ value & - & 0.0286 & 0.0488 & 0.0114 & 0.994 & 0.8136 \\
\hline & Number of observations & 225 & 208 & 214 & 192 & 201 & 177 \\
\hline \multirow[t]{3}{*}{ Competence 1} & Correlation coefficient & -0.15184 & 1 & 0.39356 & 0.24354 & 0.33477 & 0.58939 \\
\hline & $P$ value & 0.0286 & - & $<.0001$ & 0.0008 & $<.0001$ & $<.0001$ \\
\hline & Number of observations & 208 & 208 & 203 & 185 & 193 & 177 \\
\hline \multirow[t]{3}{*}{ Competence 2} & Correlation coefficient & -0.13489 & 0.39356 & 1 & 0.35619 & 0.43166 & 0.69005 \\
\hline & $P$ value & 0.0488 & $<.0001$ & - & $<.0001$ & $<.0001$ & $<.0001$ \\
\hline & Number of observations & 214 & 203 & 214 & 190 & 197 & 177 \\
\hline \multirow[t]{3}{*}{ Competence 3} & Correlation coefficient & 0.18225 & 0.24354 & 0.35619 & 1 & 0.58387 & 0.75092 \\
\hline & $P$ value & 0.0114 & 0.0008 & $<.0001$ & - & $<.0001$ & $<.0001$ \\
\hline & Number of observations & 192 & 185 & 190 & 192 & 184 & 177 \\
\hline \multirow[t]{3}{*}{ Competence 4} & Correlation coefficient & -0.00053 & 0.33477 & 0.43166 & 0.58387 & 1 & 0.85861 \\
\hline & $P$ value & 0.994 & $<.0001$ & $<.0001$ & $<.0001$ & 201 & $<.0001$ \\
\hline & Number of observations & 201 & 193 & 197 & 184 & - & 177 \\
\hline \multirow[t]{3}{*}{ Total } & Correlation coefficient & -0.01785 & 0.58939 & 0.69005 & 0.75092 & 0.85861 & 1 \\
\hline & $P$ value & 0.8136 & $<.0001$ & $<.0001$ & $<.0001$ & $<.0001$ & - \\
\hline & Number of observations & 177 & 177 & 177 & 177 & 177 & 177 \\
\hline
\end{tabular}

6 Variables: year competence1 competence 2 competence 3 competence 4 total Spearman Correlation Coefficients Prob > $|r|$ under H0: rho=Number of Observations. 
competence. Benner (1984:13-34) postulates that learners at this level may be competent, but they still lack adequate experience that would enable them to holistically manage situations which would require them to prioritize their actions. As their levels of responsibility increase, so would their realisation that their associates are fallible and can make mistakes, thus resulting in decreased trust in their peers' performance. This is consistent with the fact that, although learners have higher feelings of competence with increased levels of training, the lack of clinical experience, in particular, may still cause them anxiety that they will not meet expectations to perform competently in the workplace (Heslop, McIntyre \& Ives 2001:631-633). At the level of thirdyear, learners in the study were more exposed to clinical experiences than to the academic setting. These learners were also subjected to more traditionally based teaching and assessment methods, but their increased exposure to clinical situations could significantly have contributed to their higher levels of competence. They had more access to opportunities for skills development in the clinical setting, where experiential learning was indirectly applied, because they could relate previous experiences to new learning, which would foster the development of understanding. Dunphy and Williamson (2004:111) indicate that the competent learner can handle more complex situations, perform well in familiar situations and anticipate the normal progression of events.

\section{Feelings of competence in fourth-year learners}

Fourth-year learners did not demonstrate increased performance at the proficiency level, despite what was evidenced by their feelings of competence, and even though they had more exposure to clinical experiences. At a proficient level learners are expected to be able to make the right judgments and make critical connections between theory and practice due to previous experience (Benner 1984:13-34). Proficient learners are able to observe and interpret given situations, make decisions and quickly respond accordingly. Findings of the study did not reveal this. At fourth-year level, learners were expected to start making the transition from their roles as university learners to the roles they would fulfil in the workplace. This challenge is not unique to UWC. Morolong and Chabeli (2005:38) evaluated the competence of newly qualified registered nurses, and concluded that the nurses were not competent, with their existing knowledge and skills, to provide a nursing diagnosis - thus critical thinking skills were lacking - and they lacked an appropriate approach to provide quality nursing care. May et al. (1999:110) also pointed out that only once nursing learners become practising registered nurses, will critical thinking evolve more directly with clinical competence, and found that there was no statistically significant relationship between critical thinking and clinical competence in senior nursing learners. The study conducted by Del Bueno (1990:290-294) revealed that after completion of an educational programme, new graduates needed at least eight months of experience in the clinical field before they could practise confidently and competently. This questions how much traditional methods of teaching and assessment - which were central to these learners' current curriculum - prepare learners to adequately fulfil workplace requirements. Due to curriculum arrangements, the fourthyear learners are in the clinical and academic settings for certain blocks of time only. During these blocks, assessment is driven more by content than performance. This implies a purely traditional approach to practice as the quality and extent of learning are evaluated per practice or class session, and the achievement of competencies is thus limited by time constraints. Competence will not necessarily be achieved during a set period, such as one class or a seven-week academic term, and learners should rather be provided with guided and un-judged learning periods until verification of their competence is required. This approach will thus allow learners to learn at their own pace and in a self-directed way, and allow them to be assessed on their performance continuously until performance has improved to the level of competency (Malan 2008:23-25).

\section{Limitations of the study}

1. This study did not clearly distinguish between competence and performance, but has applied the concepts interchangeably. This may be ambiguous as competence may be interpreted as performance and vice versa.

2. Academic and clinical competence were combined in the questions presented in the data collection instrument, and were not presented individually. The researcher is of the opinion that more different responses might have been elicited if these two facets were presented as separate parts in the instrument.

3. The data collection instrument consisted of only closeended questions. Different views might have been obtained, from learners on their actual feelings of competence, if open-ended questions were also built into the questionnaire.

\section{Recommendations}

1. More studies should be done in the School of Nursing at UWC, to explore teaching and learning approaches that will fully maximise the clinical and theoretical competencies of learners.

2. Learner-centred teaching approaches, such as Case-based method, should be applied to all year levels of study in the B.Cur programme, due to its proven value when it was applied for first-year learners.

3. In-service training of teaching staff should be undertaken on various teaching approaches that stimulate critical thinking and reflective learning in learners, in order to improve nursing competence.

\section{Conclusion}

The results of the study confirm the strengths of the Casebased clinical reasoning approach to teaching and learning, which is its ability to combine the strengths of the traditional methods, in terms of large class sizes as well as its focus on learner-centred learning, with a focus on clinical practice. The Case-based clinical reasoning approach to learning, that has been implemented at the school, promotes competence 
and self confidence in learners. It has enhanced a sense of responsibility among learners to be actively involved in their own learning. It also promotes collaborative learning as learners work in groups to solve complicated problems, like they would in a real clinical situation. This approach provides realistic opportunities for learners to experiment with solutions to dilemmas encountered in real life situations, but in the protected and safe environment of the classroom. It is for this reason that first-year learners in this study expressed increased feelings of competence although they were novices. It is worth mentioning, for the reader, that by the time of writing this article, the Case-based clinical reasoning approach had been rolled out to the entire fouryear programme.

\section{Acknowledgements}

Prof. R. Madsen for providing direction with the data analysis.

\section{Competing interest}

The authors declare that they have no financial or personal relationships which may have inappropriately influenced them in writing this paper.

\section{Authors' Contributions}

T.D.K. (University of the Western Cape) provided guidance and supervision throughout the duration of this project. L.Zl.R. (University of the Western Cape) wrote the manuscript.

\section{References}

Benner, P., 1984, From novice to expert excellence and power in clinical nursing practice, Addison-Wesley, Menlo Park, CA.

Brockopp, D.Y. \& Hastings-Tolsma, T., 1995, Fundamentals of Nursing Research, 2nd edn., Jones and Bartlett, London.
Competency International SA., 2000, Competency Based Assessment Workshop, Department of Health, Cape Town.

Cormack, D., 2000, The research process in nursing, 4th edn., Blackwell Science, Oxford.

Del Bueno, D.J., 1990, 'Experience, education, and nurses' ability to make clinical judgments', Nursing \& Health Care 11(6), 290-294. PMid:2359541

Dunphy, B.C.\&Williamson, S.L., 2004, 'In pursuit of expertise',Advancesin HealthSciences Education 9, 107-127. http://dx.doi.org/10.1023/B:AHSE.0000027436.17220.9c, PMid:15141129

Ertmer, P.A. \& Russel, J.D., 1995, 'Using case studies to embrace Instructional design education', Educational Technology 35(4), 23-31.

Hek, G., Judd, M. \& Moule, P., 2003, Making sense of research, 2nd edn., Sage publications, London.

Heslop, L., Mcintyre, M. \& Ives, G., 2001, 'Undergraduate student nurse expectations and their self reported preparedness for the graduate year role', Journal of Advanced Nursing 36(5), 626-634. http://dx.doi.org/10.1046/j.13652648.2001.02022.x, PMid:11737494

Higgs, J. \& Jones, M.A., 2000, 'Clinical reasoning in the health professions', 2nd edn., Elsevier, Great Britain.

Hoke, M.M. \& Robbins, L.K., 2005, 'The impact of active learning on nursing students' clinical success', Journal of Holistic Nursing 23(3) 348-355. http://dx.doi. org/10.1177/0898010105277648, PMid:16049122

Khanyile, T. \& Mfidi, F., 2005, 'The effect of curricula approaches to the development of the student's clinical reasoning ability', Curationis 28(2), 70-76. PMid:16045113

Malan, S.P.T., 2000., 'The 'new paradigm' of outcomes-based education in perspective', Tydskrif vir Gesinsekologie en Verbruikerswetenskappe 28:22-28.

May, B.A., Edell, V., Butell, S., Doughty, J. \& Langford, C., 1999, 'Critical thinking and clinical competence: A study of their relationship in BSN seniors', Journal of Nursing Education 38(3), 100-110.

Mcmullan, M., Endacott, R., Gray, M.A., Jasper, M., Miller, C.M.L. \& Scholes, J., 2002, 'Portfolios and assessment of competence: a review of literature', Journal of Advanced Nursing 41(3), 283-294. http://dx.doi.org/10.1046/j.13652648.2003.02528.x, PMid:12581116

Morolong, B.G. \& Chabeli, M.M., 2005, 'Competence of newly qualified registered nurses from a nursing College', Curationis 28(2), 38-50. PMid:16045110

Neary, M.,2001, 'Responsiveassessment:assessingstudent nurses'clinicalcompetence', Nurse Education Today 21(3), 3-17. http://dx.doi.org/10.1054/nedt.2000.0508, PMid:11162253

Piercey, C., 1995, 'Assessing clinical competencies, in L. Summers (ed.)., A Focus on Learning, 206-211. Proceedings of the 4th Annual Teaching Learning Forum, Edith Cowan University, February 1995, Edith Cowan University, pp. 206-211.

Rhodes, M.L. \& Curran, C., 2005, 'Use of the human patient simulator to teach clinical judgment skills in a baccalaureate nursing program, Computers, Informatics', Nursing 23, 256-262.

South African Oxford School Dictionary, 2004, Oxford University press, Oxford.

Spence, W. \& El-Ansari, W., 2004, 'Portfolio assessment: practice teachers' early experience', Nurse Education Today 24:388-401. http://dx.doi.org/10.1016/j. nedt.2004.04.005, PMid:15245862

Uys, L.R., 2003, Fundamental Nursing, Maskew Miller Longman, Cape Town. 